\title{
The Larvatron: a computer-controlled apparatus for rearing planktonic animals under experimental conditions
}

\author{
Christopher J. Jackson, Robert C. Pendrey, Peter C. Rothlisberg \\ CSIRO Marine Laboratories, Division of Fisheries, PO Box 120, Cleveland, Queensland 4163, Australia
}

\begin{abstract}
The Larvatron completely automates the labor-intensive task of maintaining large-scale factorial experiments on planktonic animals, using up to 200 rearing vessels. Experiments involving a range of salinities, temperatures, food types and/or food densities can be conducted. The device is controlled by a personal computer, and experimental conditions required in each rearing vessel are defined in a computer file. The rearing vessels are moved continuously around a closed-circuit spiral track. On each circuit, as each vessel reaches a sampling station, a portion of the culture medium is withdrawn and replaced with fresh medium made up under computer control with the appropriate salinity, temperature and food concentration. The Larvatron has the following advantages: complete flexibility in experimental design, since the treatments are specified only by software; no position effects; minimal labor requirements; and no variability due to manual handling. Two experiments were undertaken with a 20 -vessel prototype to test and validate the system. These examined the effects of temperature, salinity and food concentration on growth and survival of larval Penaeus merguiensis and $P$ esculentus.
\end{abstract}

\section{INTRODUCTION}

Studies of the physical and biological needs of planktonic animals generally place 2 requirements on the experimental apparatus. Firstly, several variables should be studied in factorial combination. There is litthe value in studying the effects of a single variable in isolation, since synergistic or antagonistic interactions of variables are likely (Underwood 1981, Robert et al. 1988). However, even relatively modest factorial experiments typically require a large number of experimental treatments to be set up and maintained. In many studies using factorial experimental designs, it has not been possible to study the effects of all conditions simultaneously because of the size and complexity of the experiment. In these cases, subsets of the total experimental design have been run at different times (e.g. Kuban et al. 1985, Cadman \& Weinstein 1988). However, this procedure is not valid unless some animals are maintained under the same conditions during each successive experiment (e.g. Johns
1981), since other (non-experimental) factors such as water or food quality may also change between experiments. Other studies have included non-orthogonal experiments, which do not examine the full range of combinations of the experimental variables (e.g. Dawirs 1979, Teshima \& Kanazawa 1983). Such designs are difficult to interpret and may not reveal important interactions between experimental factors.

The second requirement is to adequately replicate each experimental treatment. The growth and survival of planktonic animals can be influenced by many factors that are not part of the experimental design (e.g. disease, individual variation). Experimental results can be variable and difficult to repeat, therefore as many as 5 replicates have been recommended in order to obtain reliable and statistically significant results from factorial experiments (Wilkenfeld et al. 1983).

Many experimental systems have been used. Some studies have been performed with pilot or hatcheryscale equipment, although this is generally only feasible with simple experimental designs (Hirata et al. 
1975, Tobias-Quinitio \& Villegas 1982). Most studies use small containers (e.g. Bookhout \& Costlow 1974, Laughlin \& Neff 1979, Rothlisberg 1979, Teshima et al. 1986, Diaz 1987, Kurmaly et al. 1989). Wilkenfeld et al. (1983) described a protocol for rearing shrimp larvae which uses an array of up to 501 -litre Imhoff cones. These containers were chosen on the basis of small volume (allowing full water exchange and convenient monitoring), and a shape that reduces the settling of larval food. This system is a valuable attempt to standardize techniques and allow adequate replication. It has been used successfully in a range of small-scale studies on larval prawn feeding (Kuban et al. 1983, 1985, Fuze et al. 1985, Samocha et al. 1989, Biedenbach et al. 1990). Survival of larvae in these studies has generally been high $(>80 \%)$ under the most favourable conditions, and variation between replicates has been low.

Despite such recent advances, there remain many problems with existing methods of maintaining factorial experiments. The work involved in changing the water and monitoring and adding food to many separate containers may limit the total size of the experiment, forcing compromises in its design. The number of levels of each experimental variable may be limited by circumstance, e.g. it may be impracticable to maintain stocks of seawater at sufficient different salinities, or too few environmental cabinets or water baths may be available for the desired range of temperatures. Within the cabinets or baths, there may be gradients in temperature or light intensity that are difficult to monitor but which can influence growth and survival of the experimental animals or their algal food. Some animals may react adversely to handling stress as water is changed, and this may contribute to variation in results. Feeding and changing water daily or less frequently cycles metabolite levels and food abundance, with possible effects on growth or survival. Finally, the cost of labor to conduct such comprehensive experiments is often prohibitive.

These considerations led us to examine methods of automating the maintenance of experimental plankton cultures. Some workers have used computers to maintain continuous-flow algal cultures (Fenaux et al. 1985, Hill et al. 1985, Miller 1987) and to maintain constant levels of turbidity in experiments on filter feeders (Sinnet \& Davis 1983, Grecay 1989). However, these devices use little of the potential power of modern personal computers, using them merely to log data or implement a simple feedback control algorithm. Grimsen et al. (1986) developed a rearing system in which juvenile lobsters were maintained in separate compartments and, through a computer-controlled device, fed with amounts calculated according to the individual's age. However the system was unreliable.
The aim of this work was to develop a fully automated zooplankton culture facility to allow us to conduct large-scale factorial experiments. We wanted to achieve a high degree of flexibility in experimental design. The resulting device, the Larvatron, takes advantage of the flexibility offered by a personal computer to control and monitor all aspects of the system. The Larvatron, and some preliminary experimental results achieved with a prototype device, are described in this paper.

\section{DESCRIPTION OF THE LARVATRON}

There are 3 major components in the Larvatron: the rearing vessels and their transport system; the culture media make-up and exchange system; and the personal computer with its controlling program. These are described in detail below

\section{Rearing vessels and transport system}

The individual rearing vessels are modified $1.5 \mathrm{l}$, plastic (polyethylene terephthalate), round-bottomed soft-drink bottles (inset, Fig. 1; B, Fig. 2). The Larvatron has a capacity of 200 bottles (Fig. 1). It is housed in a temperature-controlled room, with the air temperature set below the lowest experimental temperature. Therefore, all experimental temperatures are maintained by heating the culture water above this ambient temperature. A $15 \mathrm{~W}$ heating element is wound around the lower section of each bottle ( $\mathrm{H}$, Fig. 2) and held in place by heat-resistant adhesive tape. Above the heating element a temperature sensor (TS, Fig. 2) is attached to the outside of the bottle with epoxy resin. Both the heating element and the temperature sensor are wrapped in a thermal insulating layer of polyethylene foam (inset, Fig. 1; I, Fig. 2).

Each bottle is suspended by its neck from a carrier (C, Fig. 2). The carrier has a single wheel (W, Fig. 2), which rolls along a track of extruded aluminium (TR, Fig. 2). A custom-designed thermostat is mounted on each carrier ( $T$, Fig. 2), to control the water temperature in each bottle. Twenty-one carriers are joined together by fiberglass linkages (L, Fig. 2) to form a train. The first carrier in each train contains a $35 \mathrm{~V} \mathrm{AC}$ power supply, a domestic aquarium air pump modified to operate at $35 \mathrm{~V} \mathrm{AC}$, and a speed regulator (PS, AA \& $\mathrm{SRU}$, Fig. 2). The power supply receives $35 \mathrm{~V}$ AC power from copper braid (CB, Fig. 2) laid along the aluminium track and insulated from it by a plastic strip, and provides a regulated voltage supply to power the thermostats, heating elements and air pump. The air pump aerates water in each of the train's bottles. 


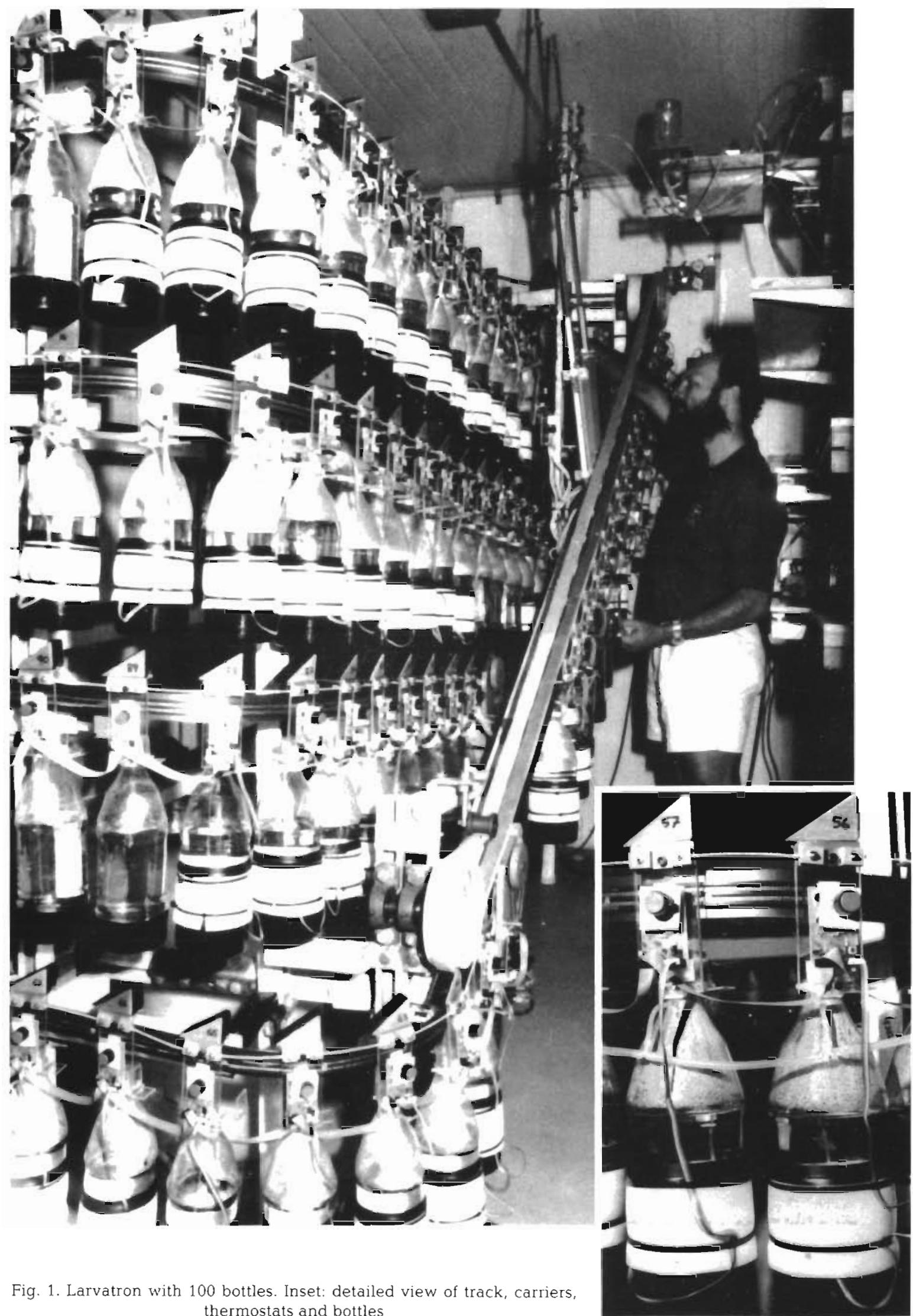




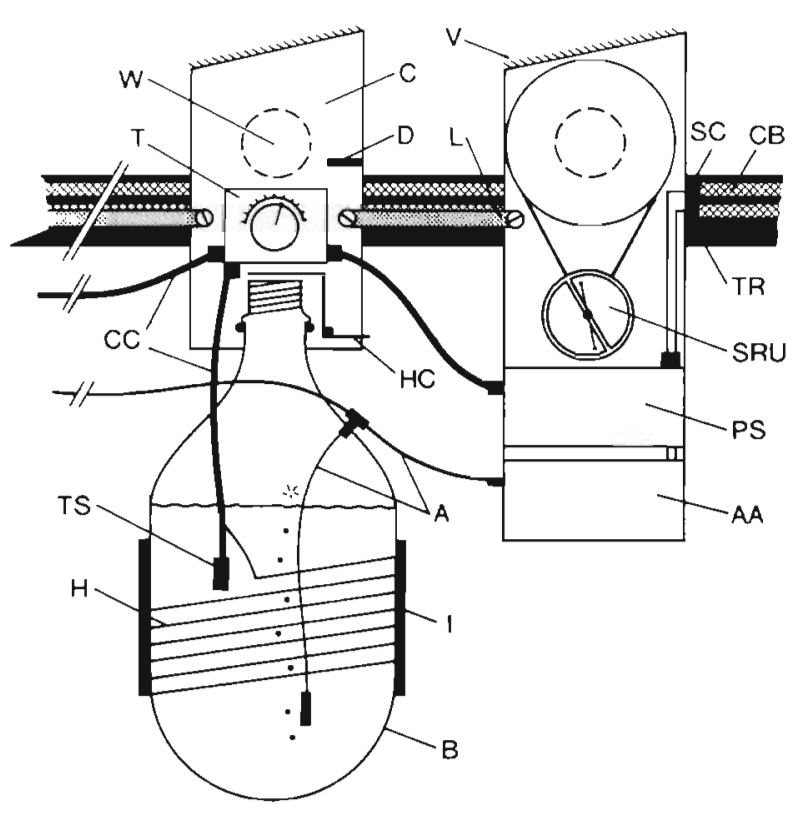

Fig. 2. Schematic representation of track, carriers and first 2 elements of train (see text for full explanation). A: air tube; AA: modified aquarium aerator; $B$ : soft-drink bottle ${ }_{i}$ C: carrier; $\mathrm{CB}$ : copper braid for distributing electricity supply; $\mathrm{CC}$ : connecting cable $\mathrm{D}$ : detection strip; $\mathrm{H}$ : heating element; $\mathrm{HC}$ : hinged plastic cover; I: thermal insulating foam; L: fiberglass link; PS: power supply; SC: sliding contact; SRU: speed regulating unit; $T$. thermostat; TR: extruded aluminium track; TS: temperature sensor; $V$ : hook component of hook-and-loop fastener (e.g. Velcro ${ }^{(1)}$ ); W: wheel

The track has a straight inclined uphill section and a spiral downhill section. An electrically driven belt transports the bottles up the incline (Fig. 1). The belt is made of the loop component of a hook-and-loop fastener (e.g. Velcro $\left.{ }^{\oplus}\right)$; this attaches to a strip of the mating hook component on the top of each carrier (V, Fig. 2). At the top of the incline, the belt peels from the carriers and, once free of the belt, the train coasts down the spiral section. The speed regulator limits the downhill speed through brake shoes activated by centrifugal force. The spiral track is $34 \mathrm{~m}$ long, allowing the use of up to 10 trains (200 bottles). At present, 5 trains are used (Fig. 1).

A sampling station is located on the uphill section of track. The bottles are positioned at the sampling station by a plastic detection strip ( $D$, Fig 2) attached to the carrier. Detection strips are of 3 lengths to keep track of bottle numbers and dose sequencing. Each strip is detected by a series of 3 light beams. When a strip is detected, the transport motor stops with the bottle accurately positioned beneath the sampling station. A hinged plastic cover (HC, Fig. 2) over the bottle mouth is opened as the sampling tube is lowered into the bottle. The tube is fitted with a screen to exclude the cultured animals from the sample of culture medium being removed. A sensor attached to the tip of the sampling tube measures the water temperature in the bottle. A second tube further along the track deliv. ers replacement medium into the bottle. The sampling and delivery tubes are pneumatically driven by modified bicycle pumps.

\section{Culture media make-up and exchange}

Water is removed from the bottles by timed operation of a peristaltic pump (Masterflex ${ }^{\otimes}$, Model 701620). Water is then pumped to a flow-through fluorometer (Turner ${ }^{(}$, Model 111) before passing to waste. Electronic dosing pumps (Iwaki ${ }^{\oplus X}$ EX series) are used for making up replacement medium. These pumps deliver a single adjustable aliquot each time an electronic signal is received from the computer. Culture medium is made up separately for each bottle at the time it is required, under computer control, according to the experimental conditions defined for the particular bottle. The appropriate volumes of distilled water, seawater and algal suspension are each transferred to a mixing chamber by separate dosing pumps. The medium is heated to the appropriate temperature before being delivered into the bottle.

\section{Computer control}

All operations of the Larvatron are controlled by a Pascal program running on a personal computer $\left(\right.$ IBM $^{\circledast}$ PC XT equivalent). An interface card (Burr-Brown ${ }^{\oplus}$ PCI-20000 series) allows input and output of digital signals and the measurement of analog voltages. A computer file (the CONDITIONS file) defines the temperature, salinity and feeding conditions for each bottle. The computer controls the following functions (Fig. 3): operating the phytoplankton, freshwater, brine and dosing pumps $(1,2,3$; Fig. 3$)$ for the make-up of culture medium, heating new culture medium to the appropriate temperature (4, Fig. 3 ) before its delivery into the bottle; operating a peristaltic pump (6, Fig. 3) to remove old medium from the culture bottle; operating a solenoid valve (7, Fig. 3) for transferring new medium into the bottle; raising and lowering the sampling tubes $(8$, Fig. 3$)$; and starting and stopping the transport motor (10, Fig. 3). The computer also monitors the water temperature ( 9 , Fig. 3 ) in each bottle and the fluorescence (5, Fig. 3) of the waste media removed from each bottle. These data, together with the date, time, bottle number and iteration number, are displayed on the computer monitor and logged in a disk file. 
Fig. 3. Schematic representation of control system

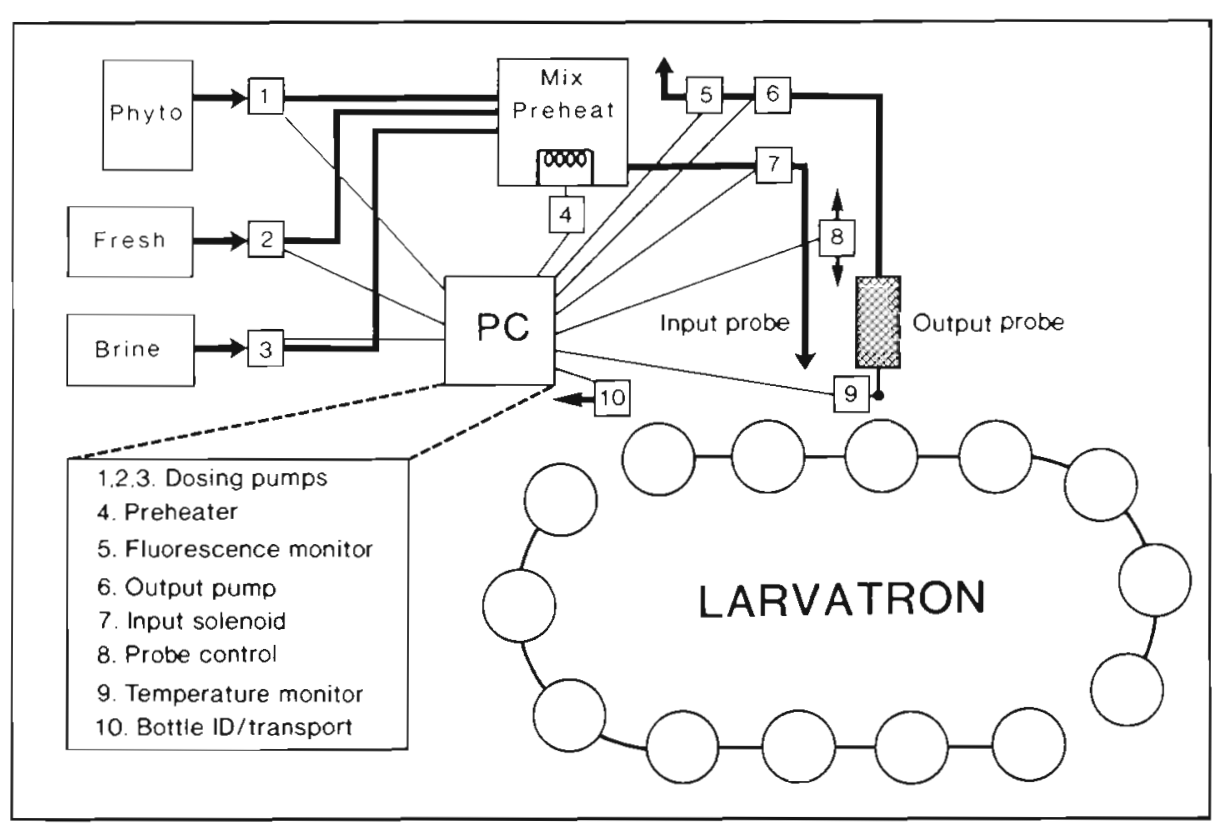

\section{Control of experimental parameters}

A stock brine solution is made up by adding artificial sea salt (Instant Ocean ${ }^{\circledR}$ Pty Ltd) to $1 \mu \mathrm{m}$-filtered seawater, until the salinity is greater than the maximum required by the experiment. During an experiment, the desired salinity in the medium added to each bottle is obtained by mixing this brine solution with distilled water, through 2 computer-controlled dosing pumps. To check the accuracy of this method, salinities were measured using a laboratory salinometer, standardized against International Standard Seawater. Over a period of $3 \mathrm{~d}$, measured salinities were always within $1.0 \%$ of the nominal value.

Algae are produced in a chemostat, and added to the replacement water by the algal dosing pump under computer control. The amount of algal suspension to be added is calculated using the desired concentration specified by the CONDITIONS file, the known concentration in the algal stock solution, and the cell concentration (calculated from fluorescence) of the water recently removed from the same bottle.

Water temperature is initially set by manually adjusting the thermostat associated with each bottle. Then, each time the computer processes a bottle the temperature is measured and compared with the desired temperature specified in the CONDITIONS file. If the temperature error is greater than $0.3^{\circ} \mathrm{C}$, a warning message is displayed on the computer screen. A historical temperature graph is also displayed for any bottles that have had deviant temperatures at any time during the previous 5 samplings. Therefore the bottle temperatures can be continually monitored and fine-tuned, if necessary, by monitoring the display screen. During initial tests, bottle temperatures were checked with a calibrated mercury thermometer, and were always within $0.3^{\circ} \mathrm{C}$ of the nominal value.

\section{Operation}

In normal operation, the controlling program runs continuously, processing experimental bottles in each pass through a loop (Fig. 4). The bottles are treated simultaneously in pairs: the first has water removed and monitored; the second is dosed with replacement seawater and food. First, the transport motor is switched on to move the next pair of bottles into their positions at the sampling station (A, Fig. 4). The lengths of the detection strips are checked with the light beams to ensure that the correct bottles are in position (B, Fig. 4). The correct number of doses of fresh water, brine and algae for the second bottle are calculated by the computer. This information is sent as pulses from the computer to the pumps, causing the appropriate quantities to be delivered into the mixing chamber (C, Fig. 4). The sampling probes are lowered, and $100 \mathrm{ml}$ of water is pumped from the first bottle. At the same time, the solenoid valve is opened to the second probe to deliver the fresh medium from the mixing chamber into the second bottle. Both temperature and fluorescence of the water removed from the first bottle are measured and logged (D, Fig. 4) (the fluorescence is then used to calculate how much algal suspension to add to the replacement medium when this bottle has been moved to the second probe). The temperature is 


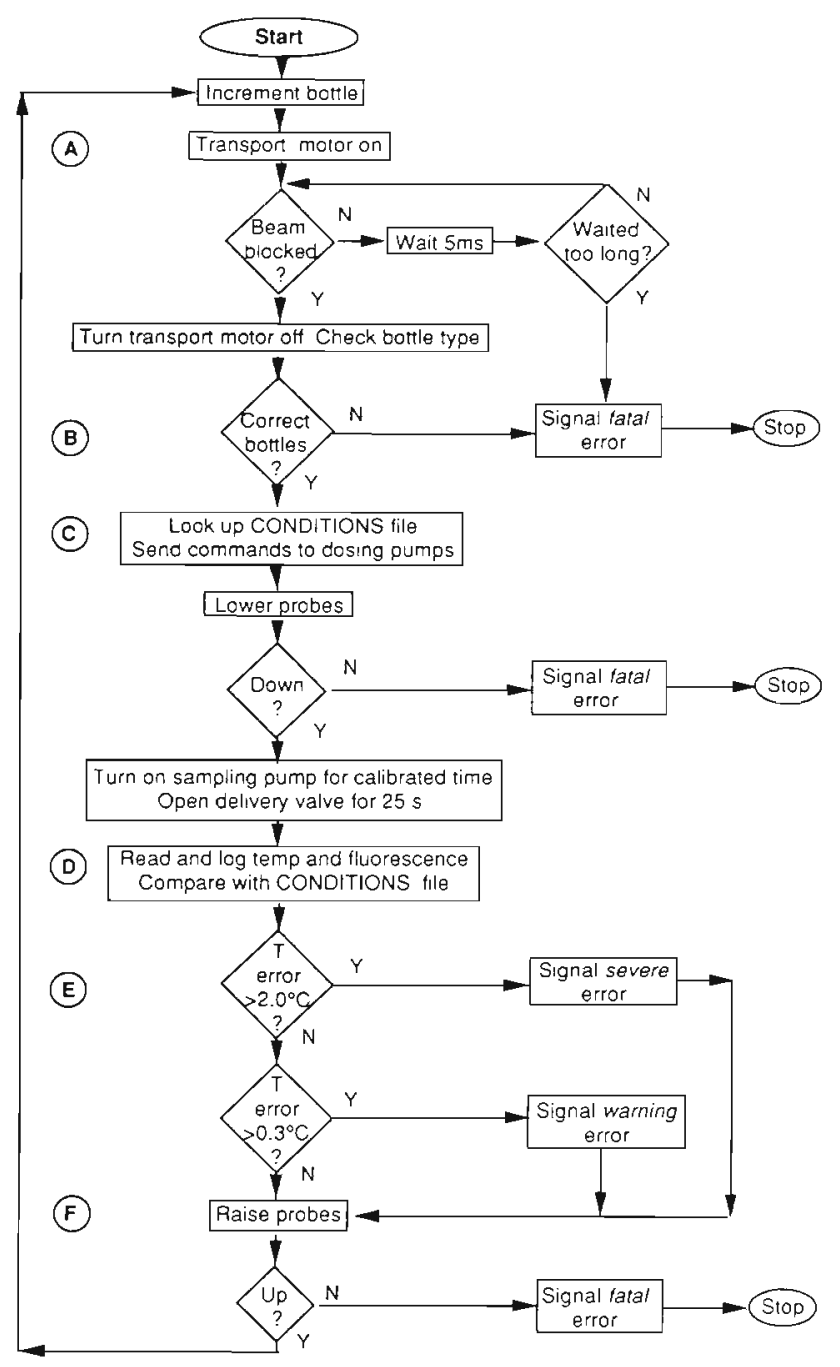

Fig. 4. Computer program flow diagram. A to F: steps in operating procedure; see 'Description of the Larvatron Operation'

also checked to ensure it is within the specified limits and, if not, appropriate errors are signalled (E, Fig, 4). The probes are raised (F, Fig. 4) and the bottles are advanced 1 position. After a timed delay, the procedure is then repeated with the next pair of bottles. Actual treatment of a pair of bottles takes about 1 . min, but the delay (which is calculated according to the total number of bottles loaded on the Larvatron) ensures that each bottle is processed 10 times each $24 \mathrm{~h}$

\section{Initial loading and salinity acclimation}

At the beginning of an experiment, all bottles are first manually filled with seawater Salinity and temperature are the same as the water in which the experimental nauplii have been maintained since hatching
In an operation which takes about $2.5 \mathrm{~h}$, nauplii are then transferred into the bottles using a custom-built electronic counter and the bottles are installed in the Larvatron.

A separate computer program enables the Larvatron to acclimate larvae to their experimental salinities at the beginning of an experiment. This program allows the salinities in all bottles to be brought to the required value in a steady, controlled sequence by periodically replacing part of their water with distilled water or brine. Program options allow for acclimation at the same rate (the same salinity change is applied to all bottles each hour, until the experimental salinity is attained) or over the same time (salinities are altered at varying rates so that all bottles reach their experimental salinities at the same time).

\section{Error-checking procedures}

Many aspects of the Larvatron's operation are continually monitored by the controlling program, but only the most important are described here. The computer is linked to the laboratory's dial-up telephone alarm system, which ensures that any problems receive attention even after working hours or on weekends. Errors are classified as warning, severe and fatal. Warning errors are simply reported on the computer screen as they occur; severe errors activate the alarm, but allow the operation of the Larvatron to continue; fatal errors stop the Larvatron and activate the alarm.

If any bottle temperature deviates by more than $2.0^{\circ} \mathrm{C}$, a severe error is displayed and the alarm is activated. In all operations where the controlling program is waiting for an event such as the closure of a microswitch or the breaking of the light beam, only a reasonable amount of time is allowed to elapse; after this, a fatal error occurs, raising the alarm, and a diagnostic message is written to the screen. This prevents damage and assists in diagnosing and rectifying any mechanical problems.

Each time a bottle is stopped at the sampling station, the size of its detection strip is checked with the light beams. By comparing this with the information present in the CONDITIONS file, it is possible to detect if the computer program has become out of step with the physical positions of the bottles. In this event, a fatal error occurs, raising the alarm and stopping operation.

\section{METHODS FOR EXPERIMENTS}

Before the Larvatron was constructed, 2 experiments were conducted using a small-scale prototype to verify the principle of operation. The main differences 
between the prototype Larvatron and the device described above were that in the prototype: the track was shorter, holding only 20 bottles in 2 trains; only a single sampling probe was used, for both removing and replacing rearing medium; batch-cultured rather than chemostat-cultured algae were used; fluorescence was not measured during the first experiment, and during the second experiment, although measured, the fluorescence was not used to calculate the amount of algal concentrate to add. There were also minor differences in the construction of the track, the power distribution method, and the materials used. The salinity acclimation program had not been developed at the time the experiments were conducted, and larvae were manually acclimated to salinity as described below.

In the first experiment, larval Penaeus merguiensis were reared at 2 temperatures $\left(24\right.$ and $28^{\circ} \mathrm{C}$ ) and 2 salinities (28.0 and $33.5 \%$ ). Each salinity-temperature combination was replicated 5 times. Nominal food concentration was kept constant $\left(2 \times 10^{4}\right.$ cells $\left.\mathrm{ml}^{-1}\right)$. Tetraselmis suecica were grown in batch cultures at $34 \%$ and $18{ }^{\circ} \mathrm{C}$, and were harvested every $3 \mathrm{~d}$. The cells were concentrated using a modified cream separator, and kept for up to 3 d at $4{ }^{\circ} \mathrm{C}$. Each day, some of this concentrate was diluted with filtered seawater and used as feeding stock for the Larvatron. T. suecica grows well between 7 and $35 \%$ and between 10 and $30^{\circ} \mathrm{C}$ (Jeffrey et al. 1992), and so its quality as food is unlikely to be affected by the less extreme conditions in the Larvatron bottles.

Gravid female prawns were trawled from commercial grounds in Moreton Bay, Queensland (27 $15^{\prime} \mathrm{S}$, $\left.153^{\circ} 15^{\prime} \mathrm{E}\right)$. In the laboratory, these prawns were held individually in $200 \mathrm{l}$ fiberglass tanks at $26^{\circ} \mathrm{C}$ and $33.5 \%$. One prawn spawned on the evening of 24 October 1989. After hatching, the nauplii were divided into 2 groups: one group was acclimated to the lower experimental salinity over $2 h_{\text {; }}$ the other remained at the ambient salinity. Groups of 100 nauplii were then counted into each of the 20 bottles and the prototype Larvatron was started. When mysis-stage larvae were visible in the most advanced cultures after $6 \mathrm{~d}$, the experiment was terminated. All larvae were preserved in $5 \%$ buffered (sodium tetraborate) formaldehyde, counted and staged.

In the second experiment, Penaeus esculentus females were trawled from Albatross Bay in the Gulf of Carpentaria $\left(12^{\circ} 45^{\prime} \mathrm{S}, 141^{\circ} 45^{\prime} \mathrm{E}\right)$. These prawns were transferred to the laboratory where they were maintained in the conditions described above, until one spawned on 1 November 1989. Three nominal concentrations of Tetraselmis suecica $\left(1,2\right.$ and $4 \times 10^{4}$ cells $\mathrm{ml}^{-1}$ ) and 2 larval stocking densities (20 and 100 larvae $1^{-1}$ ) were used in the experimental design; each set of conditions was replicated 3 times. Two controls - bottles with $2 \times 10^{4}$ cells $\mathrm{ml}^{-1}$ but no larvae - were also included. Temperature and salinity were the same in all bottles $\left(28^{\circ} \mathrm{C}, 33.5 \%\right.$ ). The prototype Larvatron was stocked with nauplii as described above (except that salinity acclimation was unnecessary) on 4 November, and the experiment was terminated after $5 \mathrm{~d}$ when mysis-stage larvae were evident. Once or twice each day, an electronic particle counter (Particle Data ${ }^{(}$, Elzone 180+) was used to measure the concentration of algae in samples of water taken from each bottle. The fluorescence of the water removed from each bottle was also logged by the on-line fluorometer, the cuvette being cleaned twice daily by a 5 min exposure to $1 \mathrm{~N} \mathrm{HCl}$ however this data was not used in calculating the amount of algal food to add to the replacement media.

To summarize the stage of development achieved by a group of larvae, a growth index (modified from Villegas \& Kanazawa 1980) was calculated as $\left(\sum A / n\right)$ where $n=$ total number of surviving larvae, and $A$ is related to the larval substage (protozoea $I, A=1$; protozoea II, $A=2$; protozoea III, $A=3$; mysis I, $A=$ 4). For example, if a sample contained 5 protozoea III and 10 mysis $I$, the growth index would be $[(5 \times 3)+(10 \times 4)] / 15=3.67$.

\section{RESULTS OF EXPERIMENTS}

The first experiment studied the effect of temperature and salinity on Penaeus merguiensis larvae. It was terminated after $6 \mathrm{~d}$ when mysis I larvae were seen in the $28^{\circ} \mathrm{C}$ treatments. Survival ranged from 28 to $100 \%$, but was highest at both temperatures at $33.5 \%$ (Fig, 5a). There was a significant effect for temperature $x$ salinity interaction on survival, with a high $F$-value for salinity (2-way factorial ANOVA, Table 1). Low salinity reduced survival more at $24^{\circ} \mathrm{C}$ than at $28^{\circ} \mathrm{C}$.

Both salinity and temperature significantly affected growth (Table 1). Larvae grew faster at the higher levels of both salinity and temperature (Fig. 5b). After $6 \mathrm{~d}$, large numbers of mysis I were present at $28^{\circ} \mathrm{C}$ and $33.5 \%$, while at $24{ }^{\circ} \mathrm{C}$ and $28.0 \%$ most larvae were still at the protozoea II substage.

The second experiment studied the effects of larval and algal food density on survival and growth of Penaeus esculentus. By comparing the fluorescence logged by the computer with the daily Tetraselmis suecica cell counts, we established the following regression:

$$
\begin{gathered}
C=-884.2+66772.1 F \\
\left(\mathrm{R}^{2}=0.994, \mathrm{p}<0.0001, \mathrm{n}=180\right)
\end{gathered}
$$

where $C=$ cell density (cells $\mathrm{ml}^{-1}$ ); and $F=$ fluorescence. This regression was then used to convert the 

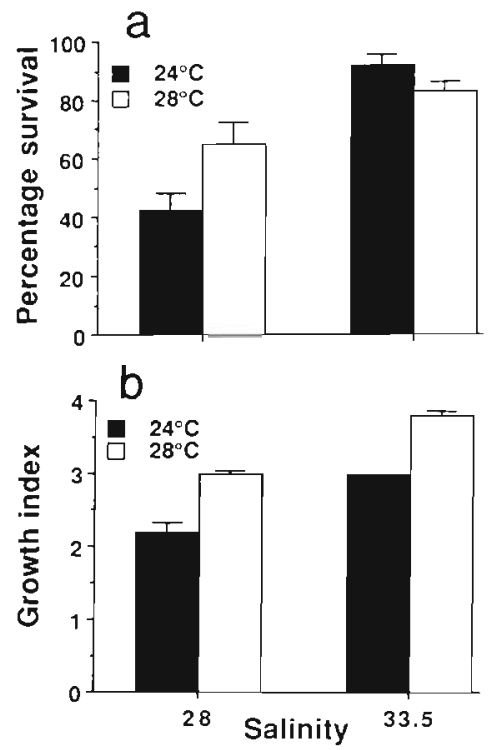

Fig. 5. Penaeus merguiensis. Mean $\pm 1 \mathrm{SE}$ of (a) percentage survival and (b) growth index after $6 \mathrm{~d}$ at 2 temperatures (24 and $28^{\circ} \mathrm{C}$ ) and 2 salinities $(28.0$ and $33.5 \%$ ). Growth index $=\sum A / n$ (see text for full description)

logged fluorescence into algal cell densities encountered by the larvae (Fig. 6). Initially, cell concentrations were close to the nominal levels defined in the CONDITIONS file. However, cell concentrations declined with time, especially at the 2 higher nominal cell concentrations (A \& C, Fig. 6). Part of this reduction can be attributed to grazing by the larvae, since in both cases, the bottles with the higher stocking densities had the lower cell concentrations (broken lines at A \& C, Fig. 6). However, some algal cells were also lost by other means, presumably settling, since the control bottles (those with no larvae present) also showed a decline in density of algal cells (B, Fig. 6).

Over $5 \mathrm{~d}$, variations in both survival (from 6 to $100 \%$ in individual replicates) and growth (from

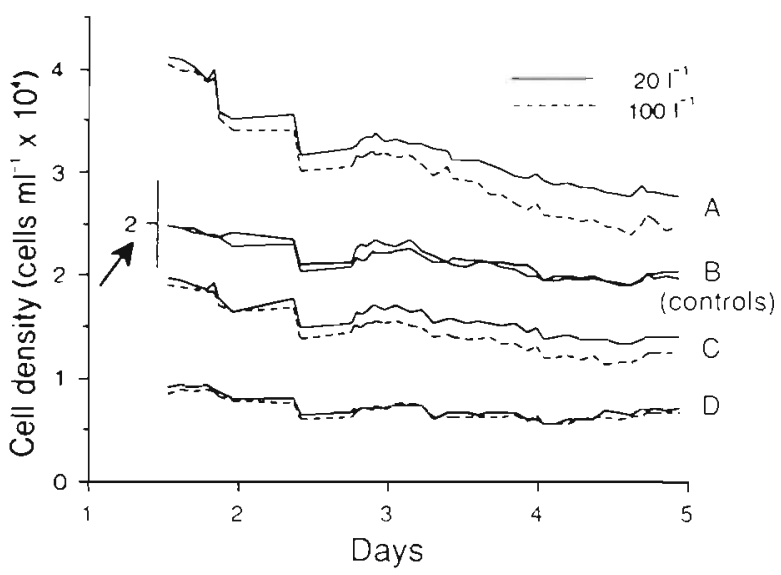

Fig. 6. Penaeus esculentus. Algal cell density, calculated from fluorescence, in 8 Larvatron bottles containing larvae over approximately $4 \mathrm{~d}$. A: nominal cell density $=4 \times 10^{4}{\mathrm{cells} \mathrm{ml}^{-1}}_{\text {; }}$ $B$ : control bottles with no larvae, nominal cell density $=2 \times 10^{4}$ cells $\mathrm{ml}^{-1}$ (note shifted $y$-axis); $\mathrm{C}$ : nominal cell density $=2 \times$ $10^{4}$ cells $\mathrm{ml}^{-1}$; D : nominal cell density $=1 \times 10^{4}$ cells $\mathrm{ml}^{-1}$. For $\mathrm{A}, \mathrm{C}$ and $\mathrm{D}$, solid line $=20$ larvae $\mathrm{I}^{-1}$; broken line $=$ 100 larvae $\mathrm{l}^{-1}$

protozoea I to mysis I) were evident (Fig. $7 \mathrm{a}, \mathrm{b}$ ). At 20 larvae $1^{-1}$ survival was between 70 and $80 \%$ at all 3 algal densities; while at 100 larvae $1^{-1}$ survival increased from $30 \%$ at $1 \times 10^{4}$ cells $\mathrm{ml}^{-1}$ to over $80 \%$ at $4 \times 10^{4}$ cells $\mathrm{ml}^{-1}$ (Fig. 7a). The growth index was higher at the lower larval stocking density, at each of the 3 feeding rates (Fig. 7b). Each increase in the algal concentration also resulted in a higher growth index. Neither larval stocking density nor food concentration had a significant effect on larval survival, but both significantly affected growth (ANOVA, Table 2). Interaction between the effects of stocking density and food concentration on the growth index was also slightly significant, because of the increase in the index at the highest food concentration in the highest stocking density.

Table 1. Penaeus merguiensis. Analysis of variance results for survival and growth of larvae after $6 \mathrm{~d}$ exposure to factorial combinations of 2 temperatures $\left(24\right.$ and $28^{\circ} \mathrm{C}$ ) and 2 salinities $\left(28.0\right.$ and $33.5 \%$ ) ${ }^{\circ} p<0.05 ; \cdots p<0.001$

\begin{tabular}{|c|c|c|c|c|c|}
\hline Source of variation & df & SS & MS & $F$ & $p$ \\
\hline \multicolumn{6}{|l|}{ Survival } \\
\hline Temperature & 1 & 245.0 & 245.0 & 1.62 & 0.2211 \\
\hline Salinity & 1 & 5780.0 & 5780.0 & 38.25 & $0.0001 \cdots$ \\
\hline Temperature $\times$ Salinity & 1 & 1280.0 & 1280.0 & 8.47 & 0.0102 \\
\hline Error & 16 & 2418.0 & 151.1 & & \\
\hline \multicolumn{6}{|l|}{ Growth index } \\
\hline Temperature & 1 & 3.32 & 3.32 & 117.93 & $0.0001 \cdots$ \\
\hline Salinity & 1 & 3.29 & 3.29 & 117.12 & $0.0001 \cdots$ \\
\hline Temperature $\times$ Salinity & 1 & 0.00 & 0.00 & 0.00 & 0.9584 \\
\hline Error & 16 & 0.45 & 0.03 & & \\
\hline
\end{tabular}


a
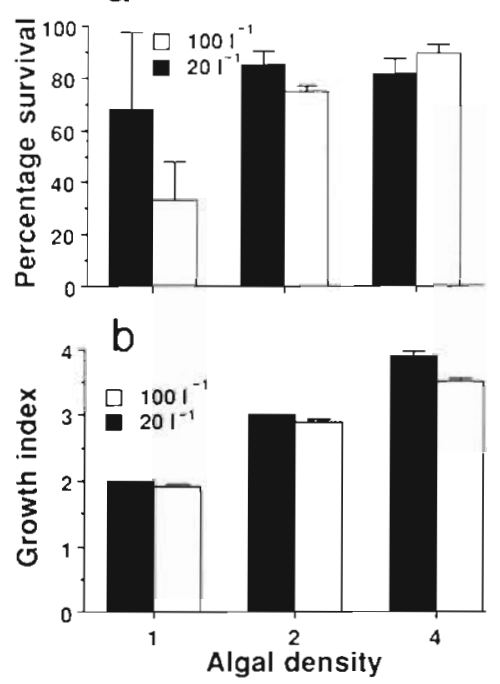

Fig. 7 Penaeus esculentus. Mean \pm 1 SE of (a) percentage survival and (b) growth index after $5 \mathrm{~d}$ at 3 food concentrations (1,2 and $4 \times 10^{4}$ cells $\mathrm{ml}^{-1}$ ) and 2 stocking densities (20 and 100 larvae $1^{-1}$ ). Growth index $=\sum A / n$ (see text for full description)

\section{DISCUSSION}

The results of the experiments verify the operation of the prototype Larvatron and demonstrate that the new device can be used to culture planktonic animals. Under favourable experimental conditions, survival through the protozoeal stages was greater than $80 \%$. similar to the survivals of controls in recent penaeid larval experiments using the Imhoff cone system (e.g. Fuze et al. 1985, Biedenbach et al. 1990). There were only 20 experimental containers in our prototype, and this limited the number of times we could replicate experimental conditions. Despite this, statistically significant differences in growth and survival due to experimental manipulation of salinity, temperature and food density were shown. Variation between replicates was low, with best coefficients of variation about $9 \%$. This compares favourably with other recent larval penaeid studies where coefficients of variation in the control or most favourable conditions were 5 to $10 \%$ (e.g. Fuze et al. 1985, Samocha et al. 1989).

The Larvatron overcomes many of the difficulties associated with former methods of conducting factorial experiments on planktonic animals. Most significantly, it allows great flexibility in experimental design through its software control of experimental conditions and acclimation regimes. The ability to process large numbers of containers makes it possible to conduct balanced factorial experiments with greater replication. The use of automated procedures to make up rearing medium and perform water exchanges, and the absence of position effects should lead to lower levels of within-treatment variability.

Grimsen et al. (1986) had problems with the reliability of their computer-controlled system for feeding juvenile lobsters. The humid environment degraded electrical contacts, and electrical interference caused faulty communication between the computer and the feeding mechanism. Any device which relies on the repeated operation of mechanical components will suffer from occasional breakdowns, and the Larvatron is no exception. However we have taken care to minimise this possibility by using non-corrosive materials wherever possible (e.g. stainless steel, fiberglass) and by using non-contact electronic sensing instead of microswitches. We conducted early trials with an 8-bit microcomputer and custom-built interfaces and, like Grimsen et al. (1986), found the equipment to be extremely sensitive to electrical noise. These problems were overcome by using the more modern IBMcompatible computer, a commercially available computer interface module, and shielded cables between the interface and the Larvatron components. However,

Table 2. Penaeus esculentus. Analysis of variance results for survival and growth of larvae after 5 d exposure to factorial combinations of 3 nominal densities of Tetraselmis suecica $\left(1,2\right.$ and $4 \times 10^{4}$ cells ml $\left.{ }^{-1}\right)$ and 2 stocking densities $\left(20\right.$ and 100 larvae $\left.\mathrm{l}^{-1}\right)$. - $p<0.05 ; \cdots p<0.001$

\begin{tabular}{|c|c|c|c|c|c|}
\hline Source of variation & $d f$ & SS & MS & $F$ & $\mathrm{p}$ \\
\hline \multicolumn{6}{|l|}{ Survival } \\
\hline Density & 1 & 722.0 & 722.0 & 1.25 & 0.2848 \\
\hline Food & 2 & 4134.3 & 2067.2 & 3.59 & 0.0600 \\
\hline Density $\times$ Food & 2 & 1374.3 & 687.2 & 1.19 & 0.3369 \\
\hline Error & 12 & 6913.3 & 576.1 & & \\
\hline \multicolumn{6}{|l|}{ Growth index } \\
\hline Density & 1 & 0.14 & 0.14 & 22.39 & $0.0005 \cdots$ \\
\hline Food & 2 & 9.18 & 4.59 & 730.94 & $0.0001 \cdots$ \\
\hline Density $\times$ Food & 2 & 0.06 & 0.03 & 4.96 & $0.0268^{\circ}$ \\
\hline Error & 12 & 0.08 & 0.01 & & \\
\hline
\end{tabular}


we accept that some errors of operation will still occur. Therefore we have employed comprehensive monitoring and error-checking, together with a dial-up telephone alarm system, to ensure that such errors will not invalidate an experiment.

The experiments were intended primarily to demonstrate the prototype Larvatron's physical operation. and the small scale of the prototype dictated a limited range of experimental conditions. Nevertheless, several important biological implications are revealed. As would be expected, the growth rate of Penaeus merguiensis was clearly affected by temperature (being greater at 28 than at $24^{\circ} \mathrm{C}$ ), and by salinity (being greater at 33.5 than at $28 \%$ ). The optimum conditions for growth are probably close to $28^{\circ} \mathrm{C}$ and $33.5 \%$, the combination which produced the fastest growth and nearly the highest survival in our trial; the average temperature and salinity at stations where $P$. merguiensis larvae have been found in the Gulf of Carpentaria is $29.2{ }^{\circ} \mathrm{C}$ and $32.3 \%$ (Rothlisberg \& Jackson 1987).

The second experiment clearly demonstrates that density of Tetraselmis suecica has an important effect on both the growth and survival of $P$. esculentus larvae. The growth rates of larvae were highest at the highest algal density studied (nominally $4 \times 10^{4}$ cells $\mathrm{ml}^{-1}$, actual concentration 2.5 to $4 \times 10^{4}$ ), and the optimum algal concentration is probably higher still. The larvae stocked at $20 \mathrm{l}^{-1}$ with a nominal algal concentration of $4 \times 10^{4}$ cells $\mathrm{ml}^{-1}$ grew faster than those stocked at $100^{-1}$. This was probably due to the lower grazing rate producing a higher actual algal density.

The grazing effect of the 2 different larval stocking densities was not consistent. At the 2 highest nominal algal concentrations, algae became less dense at the highest larval stocking density (compare broken and solid lines, A \& C, Fig. 6). However at the lowest nominal algal concentration, $1 \times 10^{4}$, the algal concentration was the same for the 2 stocking densities. Survival of the larvae in the lowest algal concentration was much lower, especially for the larvae initially stocked at $1001^{-1}$. Therefore there was a smaller actual difference in larval numbers between the 2 stocking densities, and hence a smaller difference in grazing rates. It is also possible that this lowest cell density is near the threshold for effective larval feeding; that is, the larvae do not have the capacity to filter any more water and hence reduce the algal cell concentration any further.

We are now using a 100-bottle Larvatron in studies on penaeid larvae. We are examining the salinity and temperature requirements of several species of Penaeus from the Gulf of Carpentaria. The results of these experiments will be compared with existing information about the salinity and temperature regimes in which the larvae of these species occur naturally (Rothlisberg \& Jackson 1987). We also intend to study the feeding requirements of a number of species of larvae in relation to algal species, density and nutritional quality, and to investigate the suitability of artificial feeds for prawn hatcheries.

Acknowledgements. Rex Flynn and Rod Kaden provided help in designing and building many of the Larvatron components. Michele Burford provided algal cultures for the 2 experiments.

\section{LITERATURE CITED}

Biedenbach, J. M., Smith, L. L., Lawrence, A. L. (1990). Use of a new spray-dried algal product in penaeid larviculture. Aquaculture 86: 249-257

Bookhout, C. G., Costlow, J. D. (1974). Crab development and the effects of pollutants. Thalassia Jugosl. 10: 77-87

Cadman, L. R., Weinstein, M. P. (1988). Effects of temperature and salinity on the growth of laboratory-reared juvenile blue crabs Callinectes sapidus Rathbun. J. exp. mar. Biol. Ecol. 121: 193-207

Dawirs, R. R. (1979). Effects of temperature and salinity on larval development of Pagurus bernhardus (Decapoda, Paguridae). Mar. Ecol. Prog. Ser. 1: 323-329

Diaz, G. G. (1987). Effect of environmental embryonic temperature on larval development of Macrobrachium rosenbergii (De Man). J. exp. mar. Biol. Ecol. 114: 39-47

Fenaux, R., Malara, G., Claustre, H. (1985). A turbidostat driven and controlled by microcomputer. Aquaculture 48 : $91-95$

Fuze, D. M., Wilkenfeld, J. S., Lawrence, A. L. (1985). Studies on the use of boiled chicken egg yolk as a feed for rearing penaeid shrimp larvae. Tex. J. Sci. 37: 371-382

Grecay, P. A. (1989). An apparatus for monitoring and controlling turbidity in biological experiments. Mar. Biol. 103: 421-426

Grimsen, S., Jaques, R. N., Erenst, V., Balchen, J. G. (1986) Aspects of automation in a lobster farming plant. In: Balchen, J. G. (ed.) Automation and data processing in aquaculture. Pergamon Press, New York, p. 221-224

Hill, S. H., Abbot, M. R., Denman, K. L. (1985). A computercontrolled turbidostat for the culture of planktonic algae. Can. J. Fish. Aquat. Sci. 42: 744-753

Hirata, H., Mori, Y., Watanabe, M. (1975). Rearing of prawn larvae, Penaeus japonicus, fed soy-cake particles and diatoms. Mar. Biol. 29: 9-13

Jeffrey, S. W., Leroi, J. M., Brown, M R. (1992). Characteristics of microalgal species for Australian mariculture. In: Allen, G., Dall, W. (eds.) Proceedings of the Aquaculture Nutrition Workshop, Salamander Bay, 15-17 April 1991 NSW Fisheries Brackish Water Fish Culture Research Station, Salamander Bay, Australia, in press

Johns, D. M. (1981). Physiological studies on Cancer irroratus larvae. I. Effects of temperature and salinity on survival, development rate and size. Mar. Ecol. Prog. Ser. 5: 75-83

Kuban, F. D., Lawrence, A. L. Wilkenfeld, J. S. (1985). Survival, metamorphosis and growth of larvae from four penaeid species fed six food combinations. Aquaculture 47. $151-162$

Kuban, F. D., Wilkenfeld, J. S., Lawrence, A. L. (1983) Survival and growth of Penaeus setiferus L. and Penaeus aztecus Ives larvae fed Artemia beginning at the protozoea-two substage versus the mysis-one substage. J World Maricult. Soc. 14:38-48 
Kurmaly, K., Jones, D. A., Yule, A. B., East, J. (1989) Comparative analysis of the growth and survival of Penaeus monodon (Fabricius) larvae, from protozoea I to postlarva I, on live feeds, artificial diets and on combinations of both. Aquaculture 81: $27-45$

Laughlin, R. B. Neff, J. M. (1979). Interactive effects of salinity, temperature and polycyclic aromatic hydrocarbons on the survival and development rate of the mud crab Rhithropanopeus harrissii. Mar. Biol. 53: 281-291

Miller, R. L. (1987). A computer based culturing system for measuring the photosynthetic response of phytoplankton to a fluctuating environment. J. exp. mar. Biol. Ecol. 106: $17-29$

Robert, R., His, E., Dinet, A. (1988). Combined effects of temperature and salinity on fed and starved larvae of the European flat oyster Ostrea edulis. Mar. Biol. 97: 95-100

Rothlisberg, P. C. (1979). Combined effects of temperature and salinity on the survival and growth of the larvae of Pandalus jordani (Decapoda: Pandalidae). Mar. Biol. 54: $125-134$

Rothlisberg, P. C., Jackson, C. J. (1987). Larval ecology of penaeids of the Gulf of Carpentaria, Australia. II. Hydrographic environment of Penaeus merguiensis, $P$. esculentus, $P$. semisulcatus and $P$. latisulcatus zoeae. Aust. J. mar. Freshwat. Res, 38: 19-28

Samocha, T. M., Uziel, N., Browdy, C. L. (1989). The effect of feeding two prey organisms, nauplii of Artemia and rotifers, Brachionus plicatilis (Muller), upon survival and growth of larval marine shrimp. Penaeus semisulcatus ide

This article was submitted to the editor
Haan). Aquaculture 77: 11-19

Sinnet, J. C., Davis, W. R. (1983). A programmable turbidostat for suspended particles in laboratory aquaria. J. exp. mar Biol. Ecol. 73: 167-174

Teshima, S., Kanazawa, A. (1983). Effects of several factors on growth and survival of the prawn larvae reared with microparticulate diets. Bull. Jap. Soc. scient. Fish. 49: 1893-1896

Teshima, S., Kanazawa, A., Yamashita, M. (1986). Dietary value of several proteins and supplemental amino acids for larvae of the prawn Penaeus japonicus. Aquaculture 51. 225-235

Tobias-Quinitio, E., Villegas, C. T. (1982). Growth, survival and macronutrient composition of Penaeus monodon Fabricius larvae fed with Chaetoceros calcitrans and Tetraselmis chuii. Aquaculture 29: 253-260

Underwood, A. J. (1981). Techniques of analysis of variance in experimental marine biology and ecology. Oceanogr. mar. Biol. A. Rev. 19: 513-605

Villegas, C. T., Kanazawa, A. (1980). Rearing of the larval stages of prawn, Penaeus japonicus Bate, using artificial diet. Mem. Kagoshima Univ. Res. Center S. Pacif. 1: $43-49$

Wilkenfeld, J. S., Lawrence, A. L., Kuban, F. D. (1983). Rearing penaeid shrimp larvae in a small-scale system for experimental purposes. In: Rogers, G. L., Day, R., Lim, A. (eds.) Proc. First int. Conf. warm Wat. Aquacult. Crustacea. Brigham Young Univ. Hawaii Campus, Office of Continuing Education, Laie, p. 72-81

Manuscript first received: April 24, 1992

Revised version accepted: July 30,1992 